NASA Technical Memorandum 106477

\title{
Mixing Characteristics of Directly Opposed Rows of Jets Injected Normal to a Crossflow in a Rectangular Duct
}

D.S. Liscinsky and B. True

United Technologies Research Center

East Hartford, Connecticut

and

J.D. Holdeman

Lewis Research Center

Cleveland, Ohio

Prepared for the

32nd Aerospace Sciences Meeting and Exhibit

sponsored by the American Institute of Aeronautics and Astronautics

Reno, Nevada, January 10-13, 1994 


\title{
Mixing Characteristics of Directly Opposed Rows of Jets Injected Normal to a Crossflow in a Rectangular Duct
}

\author{
D.S. Liscinsky* and B. True** \\ United Technologies Research Center \\ East Hartford, CT 06108 \\ J.D. Holdeman $\dagger$ \\ NASA Lewis Research Center \\ Cleveland, $\mathrm{OH} 44135$
}

\begin{abstract}
$\underline{\text { Abstract }}$
An experimental investigation of the mixing of nonreacting opposed rows of inline jets injected perpendicular to a uniform crossflow has been conducted in a rectangular duct. Planar Mie-scattering was used to measure the time-average concentration distribution of the jet fluid in planes perpendicular to the duct axis.

Orifice configurations with geometric blockages ranging from 0.59 to 0.89 had similar mixing performance when compared at one-half duct height downstream of injection. Blockage was varied by changing the orifice aspect ratio from 1-to-1 to 1-to-1.5 while maintaining orifice spacing-toduct height $(\mathrm{S} / \mathrm{H})$ at 0.425 , jet-to-mainstream mass flow ratio (MR) at 2.0, and jet-to-mainstream momentum-flux ratio (J) at 48 . The result indicates that the design correlating expression (at $M R=2$ ) for optimum inline mixing of $2.5 \approx(\mathrm{S} / \mathrm{H}) \sqrt{\mathrm{J}}$ is independent of the webb between adjacent orifices and therefore independent of orifice width. Experimental and numerical results for an orifice aspect ratio 1-to-1 case were in good agreement.
\end{abstract}

The results of a comparison of inline $45^{\circ}$ slanted slot and round orifice configurations indicate that in order to obtain equivalent mean concentration distributions at the same $J$ it is necessary to use a smaller $\mathrm{S} / \mathrm{H}$ for the round orifice configuration. Conclusions about the performance of various orifice shapes can only be obtained from comparison of optimized configurations.

Inline jets with different momentum-flux fatios on opposite sides were compared at a constant mass flow ratio. The orifice spacing choosen was previously found to be an optimum configuration when opposing values of $\mathrm{J}$ were equal and also an optimum for single side injection. Experimental and empirical results were in good agreement.

* Research Scientist, Member AIAA

** Senior Laboratory Technician

$\dagger$ Senior Research Engineer, Associate Fellow AIAA

\section{Nomenclature}

\begin{tabular}{|c|c|}
\hline $\mathrm{Ar}$ & jet-to-mainstream area ratio $=A_{j} / A_{m}$ \\
\hline B & blockage $=\mathrm{y}$ projection $/ \mathrm{S}$ \\
\hline C & $(\mathrm{S} / \mathrm{H}) * \sqrt{\mathrm{J}}($ see Eq. 1$)$ \\
\hline $\mathrm{c}_{\text {avg }}$ & $\begin{array}{l}\left(\mathrm{mj} / \mathrm{m}_{\mathrm{m}}\right) /\left(1+\mathrm{m}_{\mathrm{j}} / \mathrm{m}_{\mathrm{m}}\right)=\theta_{\mathrm{EB}}{ }^{17} \\
\text { orifice discharge coefficient }\end{array}$ \\
\hline DR & jet-to-mainstream density ratio $=\rho_{\mathrm{j}} / \rho_{\mathrm{m}}=1.0$ \\
\hline $\mathrm{D}$ & orifice diameter \\
\hline $\mathrm{H}$ & duct height at injection plane $=2$ in \\
\hline $\mathrm{J}$ & $\begin{array}{l}\text { jet-to-mainstream momentum-flux ratio } \\
=\left(\rho_{j} V_{j}^{2}\right) /\left(\rho_{m} V_{m}^{2}\right)\end{array}$ \\
\hline MR & jet-to-mainstream mass flow ratio $=\mathrm{m}_{\mathrm{j}} / \mathrm{m}_{\mathrm{m}}$ \\
\hline & $\begin{array}{l}\text { spacing between corresponding points on } \\
\text { adjacent orifices }\end{array}$ \\
\hline $\mathrm{U}_{\mathrm{s}}$ & spatial unmixedness parameter (see Eq. 2) \\
\hline $\mathrm{V}_{\mathrm{j}}$ & jet velocity $=m_{j} /\left(\rho_{j} A_{j} C_{d}\right)$ \\
\hline $\mathrm{v}_{\mathrm{m}}$ & mainstream velocity $=10 \mathrm{ft} / \mathrm{s}$ \\
\hline$x$ & $\begin{array}{l}\text { downstream coordinate, } x=0 \text { at the leading } \\
\text { edge of the orifice }\end{array}$ \\
\hline & oss-stream coordinate \\
\hline
\end{tabular}

\section{Introduction}

Rapid mixing of two steady flows is essential in numerous technology areas, including aeropropulsion, chemical processing, and effluent control. Injection of jets perpendicular to a crossflow has proven to be an effective mixing technique for many of these applications. For example, gas turbine combustion chambers rely on crossflow mixing in the dilution zone to provide a uniformly mixed discharge to the turbine.

Crossflow mixing has recently been proposed as a technique which will provide the rapid mixing required in a propulsion system that has low emissions. The Rich-burn/ Quick-mix/Lean-burn (RQL) combustor concept uses axially staged burning zones to avoid stoichiometric mixtures in order to minimize production of oxides of nitrogen $\left(\mathrm{NO}_{x}\right)$ while maintaining a high level of combustor efficiency. The quickmix section is a key technology for this combustor to achieve low emissions ${ }^{1}$. Evaluation and enhancement of the performance of the mixing section for this combustor concept has been the subject of many recent experimental and numerical studies of crossflow mixing ${ }^{2-16}$. The present investigation further addresses the design of this section. 


\section{Background}

The study of jet mixing in gas turbine combustor dilution zones is generally motivated by concern for turbine durability. Mixing performance in the dilution zone is determined by jet penetration and use of the "optimum" number of jets. The design is satisfactory when a uniform mean temperature distribution is achieved at the exit of the combustor ${ }^{17-19}$. Holdeman ${ }^{17}$ has shown that the most important design parameters are (1) jet-to-mainstream momentum-flux ratio $(\mathrm{J})$ and (2) orifice spacing-to-duct height ratio $(\mathrm{S} / \mathrm{H})$ and that optimum mixing performance is achieved when the product of the orifice spacing and the square root of the momentum-flux ratio are a constant:

$$
\mathrm{C}=(\mathrm{S} / \mathrm{H}) \sqrt{\mathrm{J}}
$$

The value of this constant, $C$, has been determined empirically over a range of $\mathrm{J}$ for orifices with spacing-to-diameter ratios $(S / D) \geq 2$, and $M R \leq 0.5$. Optimum mixing was obtained when $\mathrm{C}=2.5$ for single-side injection, 1.25 for opposed rows of inline jets, and 5.0 for opposed rows of staggered jets.

In the RQL combustor, the design of the mixer is constrained by the need for rapid addition of a large quantity of air at a $\Delta \mathrm{P}<4 \%$. While conventional dilution zones typically have jet-to-mainstream mass flow ratios $(\mathrm{MR}) \leq 0.5$ and may introduce the mass over a length of several combustor heights, the RQL mixer requires a mass addition of $M R \geq 2$ in a length that is less than half a duct height. Designs which achieve this mass addition therefore have high jet-to-duct area ratios compared to conventional dilution zones, the result being large orifices which are closely spaced $(\mathrm{S} / \mathrm{D} \leq 2)$. Directly opposed inline orifices provide the largest mass addition per orifice length of any geometric configuration and therefore recent experimental and numerical studies have concentrated on this orifice configuration for the RQL application. In this investigation, three design considerations for inline orifices are explored: (1) webb between adjacent orifices, (2) orifice shape, and (3) jets with different momentum-flux ratios on opposite sides.

\section{Experimental}

Figure 1 is a schematic representation of the apparatus. The apparatus consists of 3 parallel contiguous ducts of rectangular cross section, simulating a sector of an annular combustor. Sector width is 12 inches. The inner duct height $(\mathrm{H})$ is variable, but was set at 2 inches for the reported experiments. The outer ducts (shrouds), which supply the injectant gas, are 1 inch in height. These are separated from the inner duct by removable, 0.12 inch thick flat plates. The injectant is fed from the shrouds to the inner duct through orifices of various sizes and shapes that are machined into the plates. Mass flow to each of the 3 ducts is controlled independently using venturi flowmeters. The maximum variation in the mean approach velocity of the mainstream flow was $6 \%$ with a turbulence level of $1.3 \%$. All tests were conducted at unity density ratio.

Planar digital imaging was used to optically measure concentration distributions in planes perpendicular to the duct axis, starting at the leading-edge of the orifice and continuing downstream to a location equal to the duct height. The Mie scattering technique ${ }^{20}$ is applied by marking the jet flow with an oil aerosol ( $\mu \mathrm{m}$ sized particles). A light sheet ( 0.02 inch thick) is created using a $2 \mathrm{~W}$ argon-ion laser and a rotating mirror. The flow field is illuminated by passing the light sheet through a window in the side wall of the test section. An image intensified thermo-electrically cooled CCD camera, located inside the duct $2.5 \mathrm{ft}$ downstream of the orifice centerline, is focused on the illuminated plane (end-on view). The camera is programmed to make exposures coincident with the sweep of the beam through the flow field. The image is digitized and sent to a computer for storage. The scattered light intensity is proportional to the number of particles in the measurement volume. If only one of two streams is marked (in this study the jet fluid), the light intensity of the undiluted marked fluid represents mole fraction unity.

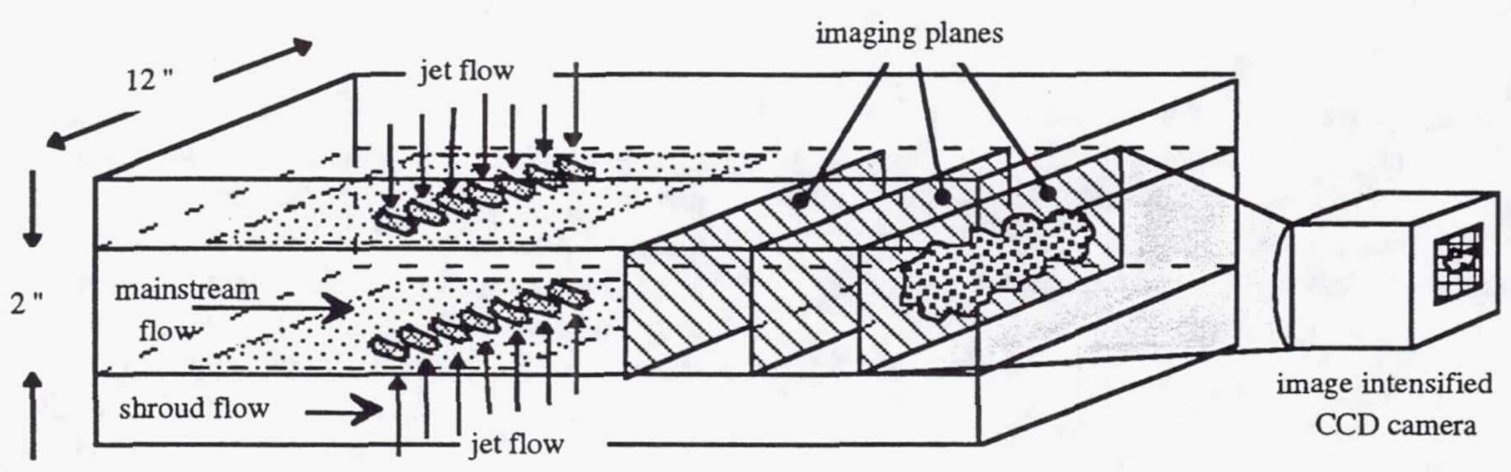

Figure 1: Experimental Configuration used to Measure Planar Concentration Distributions 


\section{Analysis}

Spatial unmixedness $\left(U_{s}\right)$ is a parameter that quantifies the unmixedness of a distribution, and discussed in detail by the authors in Ref. 7., is defined as:

$$
\mathrm{U}_{\mathrm{s}}=\frac{\mathrm{c}_{\mathrm{var}}}{\mathrm{c}_{\mathrm{avg}}\left(1-\mathrm{c}_{\mathrm{avg}}\right)}
$$

where,

$$
\begin{aligned}
\mathrm{c}_{\mathrm{var}} & =\frac{1}{\mathrm{~m}} \sum_{\mathrm{i}=1}^{\mathrm{m}}\left(\overline{\mathrm{c}}_{\mathrm{i}}-\mathrm{c}_{\mathrm{avg}}\right)^{2} \\
& =\text { spatial concentration variance } \\
\mathrm{m} & =\text { number of pixels in the distribution } \\
\overline{\mathrm{c}_{\mathrm{i}}} & =\text { time-average concentration at a pixel } \\
\mathrm{c}_{\mathrm{avg}} & =\text { fully mixed concentration }=\mathrm{m}_{\mathrm{j}} /\left(\mathrm{m}_{\mathrm{j}}+\mathrm{m}_{\mathrm{m}}\right) \\
\mathrm{c}_{\mathrm{avg}}\left(1-\mathrm{c}_{\mathrm{avg}}\right) & =\text { maximum concentration variance } \\
& =0.221 \text { for } \mathrm{MR}=2.0
\end{aligned}
$$

Normalization by $\mathrm{c}_{\mathrm{avg}}\left(1-\mathrm{c}_{\mathrm{avg}}\right)$ allows comparison of systems of different $c_{\text {avg }}$ (different MR) and bounds $U_{s}$ between 0 and $1 . \mathrm{U}_{\mathrm{s}}=0$ corresponds to a perfectly mixed system, and $U_{s}=1$ a perfectly segregated system.

\section{Results and Discussion}

\section{Effect of Blockage}

The general inverse relationship of J and S/H (Eq. 1) has been shown ${ }^{2}$ to apply when extended to RQL conditions of $\mathrm{MR}=2$ and $\mathrm{S} / \mathrm{D} \leq 2$. However at those conditions, the proportionality constant, C, has been found, both experimenally ${ }^{7}$ and numerically ${ }^{2} \& 6$, to be $\approx 2.5$, compared to a value of 1.25 which was reported ${ }^{17}$ at $S / D \geq 2$. To determine whether $\mathrm{C}$ is a function of orifice width, a set of "optimized" orifices with varying geometric blockages (B) were investigated. Rectangularly shaped orifices were used in order to maintain $\mathrm{MR}=2.0$ and $\mathrm{S} / \mathrm{H}=0.425$ for all configurations. (Blockage cannot be varied at constant MR and S/H using circular orifices).

\begin{tabular}{|c|c|c|c|c|c|c|}
\hline $\begin{array}{c}\text { Plate } \\
\#\end{array}$ & $\begin{array}{l}\text { Aspect } \\
\text { Ratio }\end{array}$ & Configuration & $\begin{array}{c}\text { Width } x \text { Length } \\
\left(\Delta y^{\prime \prime} \times \Delta x^{\prime \prime}\right)\end{array}$ & $\begin{array}{l}\text { Area Ratio } \\
(\mathrm{Aj} / \mathrm{Am})\end{array}$ & $\begin{array}{l}\text { Design } \\
\mathrm{Cd}\left({ }^{*}\right)\end{array}$ & Blockage $^{\dagger}$ \\
\hline 1 & 1 -to-1.5 & 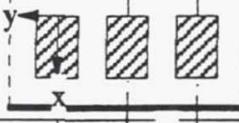 & $0.502 \times 0.752$ & 0.444 & $0.75(0.66)$ & 0.59 \\
\hline 2 & 1-to-1.25 & s.ta & $0.550 \times 0.687$ & 0.444 & $0.75(0.64)$ & 0.65 \\
\hline 3 & 1-to-1 & & $0.614 \times 0.614$ & 0.444 & $0.75(0.65)$ & 0.72 \\
\hline 4 & 1-to-1.25 & 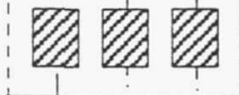 & $0.687 \times 0.550$ & 0.444 & $0.75(0.62)$ & 0.81 \\
\hline 5 & 1 -to-1.5 & & $0.752 \times 0.502$ & 0.444 & $0.75(0.62)$ & 0.89 \\
\hline 6 & $1-$ to-1 & & $0.695 \times 0.695$ & 0.444 & $0.75(0.66)$ & 0.82 \\
\hline 7 & --- & & $0.850 \times 0.44$ & 0.444 & $0.75(0.68)$ & 1.00 \\
\hline
\end{tabular}

The effect of varying blockage from 0.59 to 1.0 was investigated by testing the 7 orifice plate configurations shown in Table 1. The first 6 configurations were designed to be optimum inline mixing configurations based on the results of a numerical parametric investigation of aspect ratio and orifice spacing by Bain, Smith and Holdeman ${ }^{2}$. In that numerical study, aspect ratio and orifice shape were found to have little

Table 1: Optimum Inline Orifice Configurations for $\mathrm{MR}=2.0, \mathrm{~S} / \mathrm{H}=0.425, \mathrm{~J}=36$

- measured discharge coefficient

${ }^{\dagger}$ y projection / S 
Page intentionally left blank 
effect on the mixing performance of inline configurations when a value of 2.55 was used for $\mathrm{C}$ in Eq. 1. The plates were designed for a MR of 2.0 when $\mathrm{J}=36$ and $\mathrm{S} / \mathrm{H}=0.425$ in order to compare with those numerical results. However, the experimentally measured $\mathrm{C}_{\mathrm{d}}$ for the plates was significantly less than the design point $C_{d}$. The lower $C_{d}$ required $J=48$ to achieve $\mathrm{MR}=2$.

Average jet mass fraction concentration distributions perpendicular to the mainstream flow direction for blockages of $0.59 .0 .65,0.81$ and 0.89 are shown in Fig. 2a at 5 downstream positions starting at the trailing edge of each row of orifices. The concentration distributions are plotted using 10 color-coded contours each representing a range in jet mass fraction of 0.1 from pure jet fluid $=1.0$ (blue) to pure mainstream fluid $=0.0$ (red). The fully mixed concentration of each configuration $\left(\mathrm{c}_{\text {avg }}\right)$ is 0.667 .

In each configuration the jets penetrate to about $1 / 4$ of the duct height, which has been shown to provide optimum mixing in an inline configuration ${ }^{2}$. As the jets move downstream (top to bottom in fig. 2a) the distributions become similar, and at $\mathrm{x} / \mathrm{H}=0.5$ the distributions appear equivalent

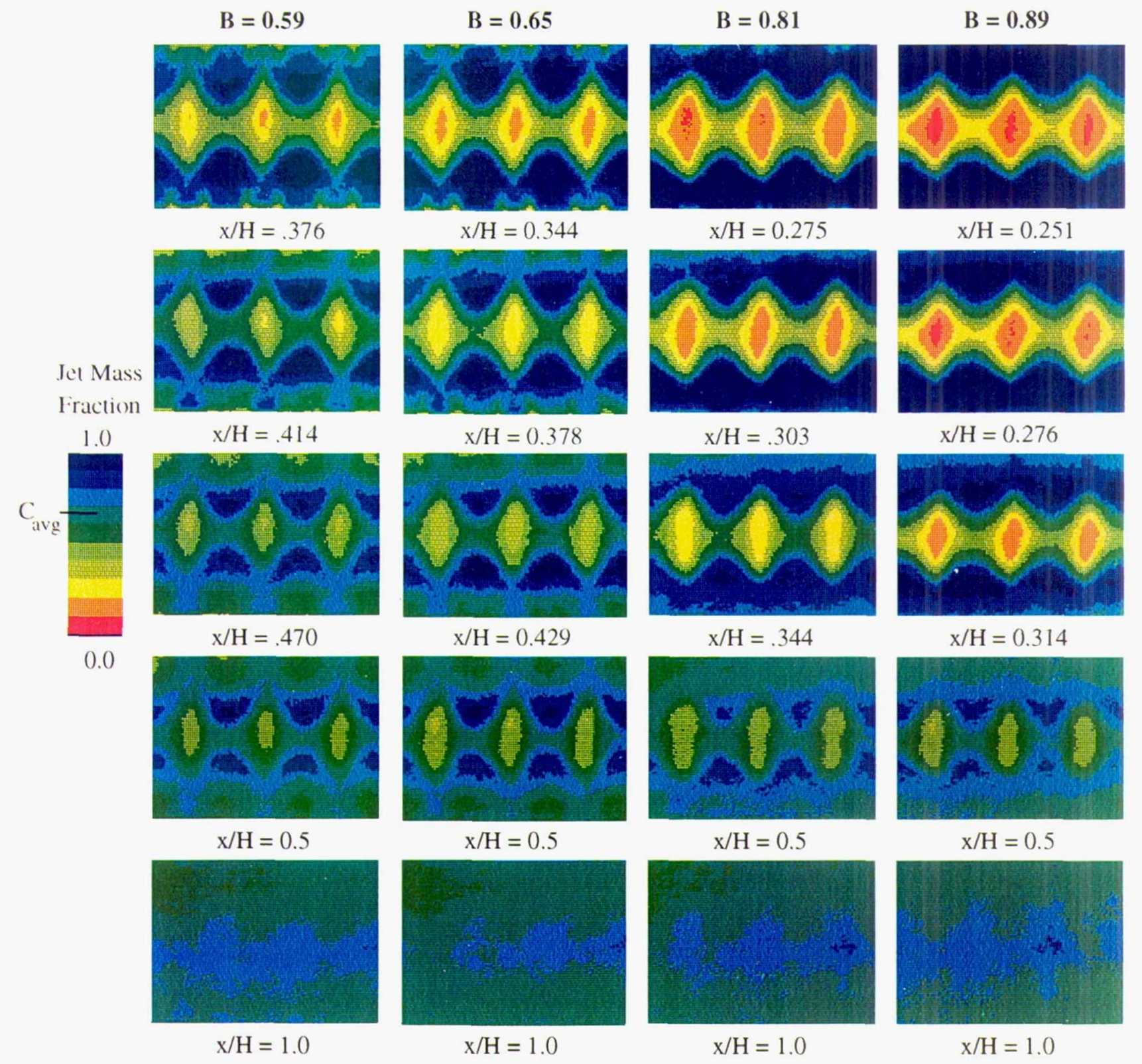

Figure 2a: Effect of Blockage on Opposed Inline Orifices at MR $=2.0, \mathrm{~S} / \mathrm{H}=0.425, \mathrm{~J}=48$ 
Page intentionally left blank 
In fig. $2 b$ average jet mass fraction concentration distributions are shown for a square $(B=0.72)$, a circle $(\mathrm{B}=0.82)$, and a $2 \mathrm{D}$ slot $(\mathrm{B}=1.0)$. The concentration distributions of the $2 \mathrm{D}$ slot indicate that the mainstream fluid remains in the center of the duct while the jet fluid stays near the walls. The mixing rate of this configuration appears lower than the cases where $\mathrm{B}<1.0$. At $\mathrm{x} / \mathrm{H}=0.5$ the distributions of the rectangular and circular configurations appear similar to each other and to the corresponding distributions in Fig. 2a.
Spatial unmixedness is plotted as a function of downstream position $(\mathrm{x} / \mathrm{H})$ for the 7 configurations in Fig. 3. The curves are similar for all configurations except the 2D slot, which is consistently less mixed as a function of $x / H$. The surprising result is that mixing is independent of $\mathrm{B}$ over a range of 0.59 to 0.89 . Similar performance independent of B can probably be attributed to the fact that the effective aerodynamic blockage is significantly less than the geometric blockage because of the vena contracta of the jet. For example, plate 3 has a blockage of 0.72 based on physical dimensions.

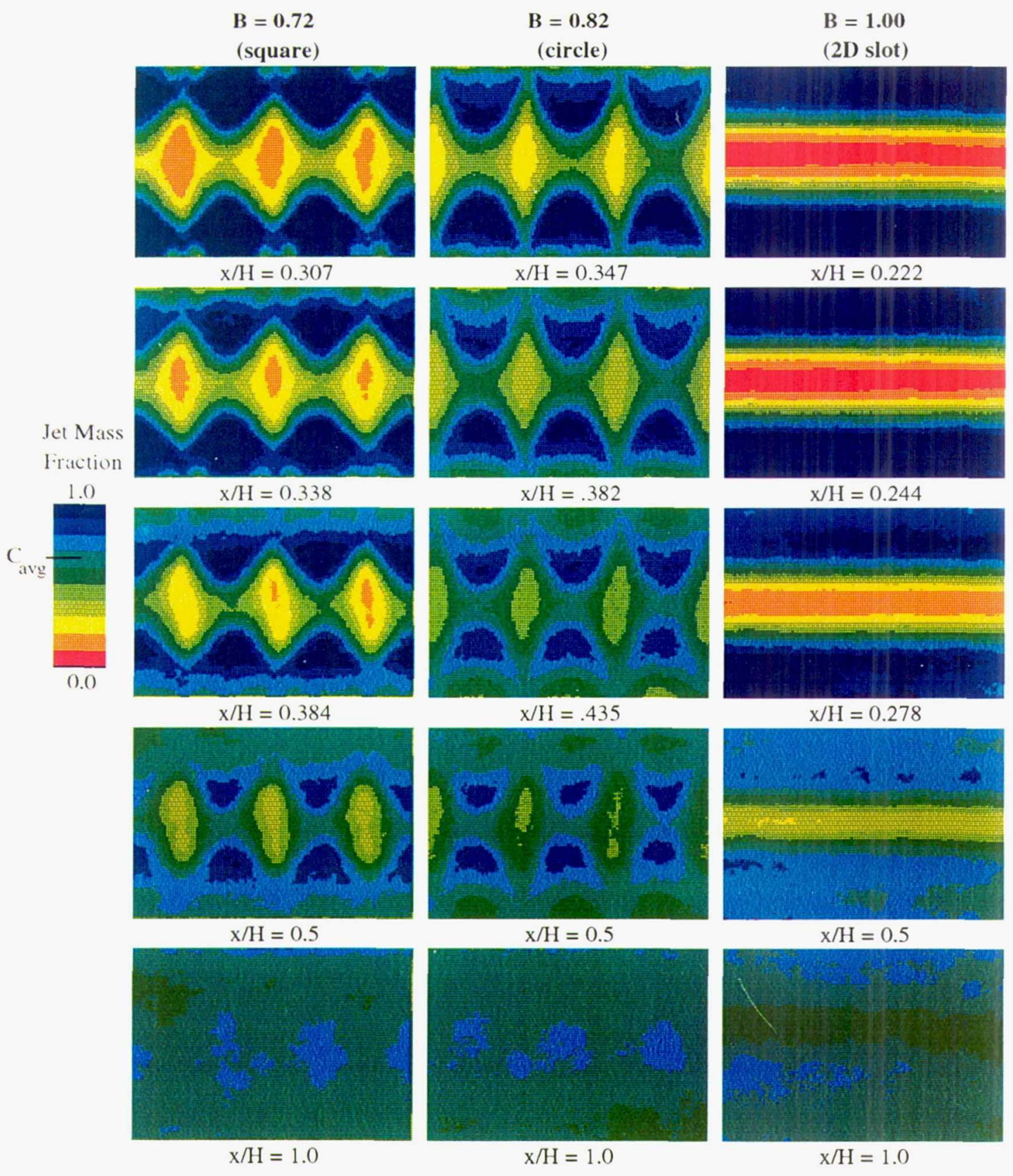

Figure 2b: Effect of Blockage on Opposed Inline Orifices at $\mathrm{MR}=2.0, \mathrm{~S} / \mathrm{H}=0.425, \mathrm{~J}=48$ 
Page intentionally left blank 


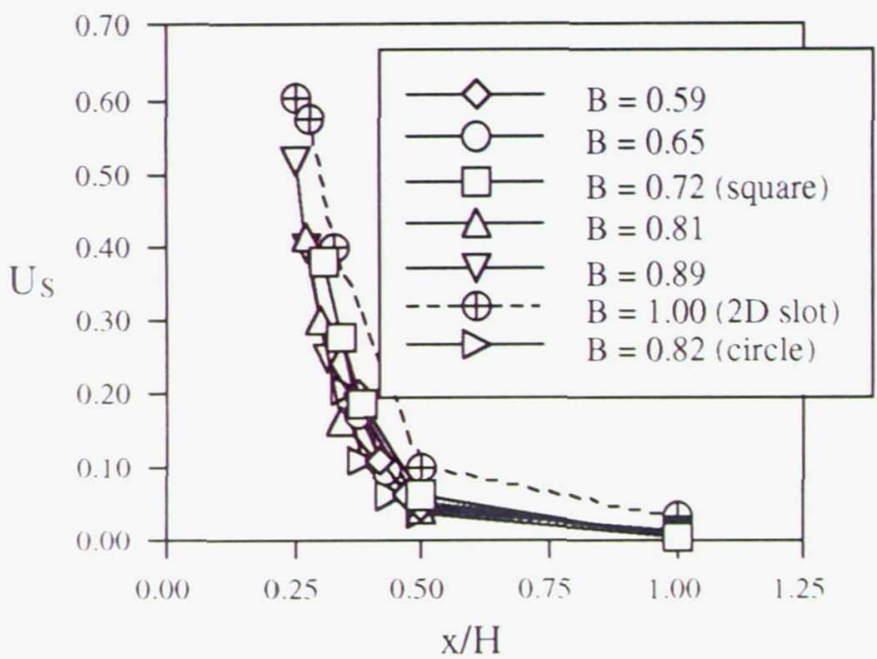

17igure 3: Fffect of Blockage on Spatial Unmixedness at $\mathrm{MR}=2.0, \mathrm{~S} / \mathrm{H}=0.425, \mathrm{~J}=48$

hut only 0.58 when $C_{d}$ is considered. Therefore even a configuration such as plate 5 that has a $B$ of 0.89 allows a significant proportion of the mainstream to pass between adjacent jets due to the vena contracta of the orifice. The shear created by mainflow passing between the jets is necessary for development of a 3D) flowfield which promotes mixing. The importance of the interplay between the jets and mainstream is evident from the concentrtation distribution of the 2D slot which confines the mainstream to the center of the duct.
As a practical design issue, the results indicate that webb thickness can be set by mechanical constraints and not aerodynamics associated with mixing performance. Eq. 1 can be used without concern for a decrease in performance due to high $\mathrm{B}$. The rate of mass addition as a function of downstream distance can therefore be increased by reduction of webb thickness so that the axial length of the orifice can be minimized. Furthermore, circular and rectangularly shaped orifices with aspect ratios between 1-to-1 and 1-to-1.5 in both bluff and aligned orientations have similar levels of $U_{s}$ at $\mathrm{x} / \mathrm{H}=0.5$, but note that the bluff orientation offers the characteristic of smaller $x$ projection per unit area.

\section{Experimental and Numerical Results}

A comparison of the experimental and numerical ${ }^{2}$ jet mass fraction concentration distributions for the square orifice configuration (plate 3 in Table 1 ) is shown in Fig. 4 at the trailing edge of the orifice and at $\mathrm{x} / \mathrm{H}=0.5$. In each case $\mathrm{S} / \mathrm{H}=0.425$ and $\mathrm{J}=36$. $\mathrm{C}_{\text {atg }}$ for both distributions falls within the $7^{\text {th }}$ contour (the experimental MR was $1.7\left(c_{\text {avg }}=0.63\right.$ ) compared to the numerical MR of $2.0\left(\mathrm{c}_{\mathrm{avg}}=0.67\right)$ ). At each of the downstream locations the number of contours and jet penetration are in agreement. Unmixedness of the two cases is compared in Fig. 5. Good agreement is obtained at $x / H \geq 0.5$. but note that upstream of this location the curves appear to diverge.

\section{Experimental Result}

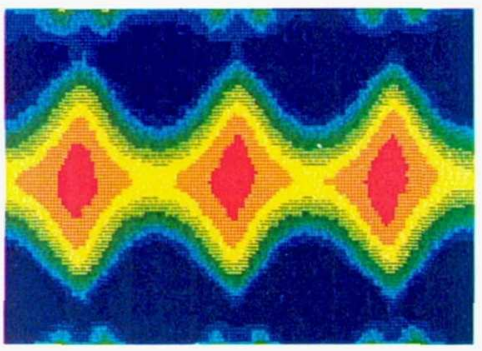

$\mathrm{x} / \mathrm{H}=0.307$

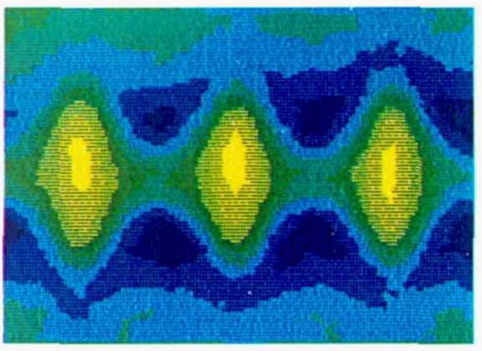

$\mathrm{x} / \mathrm{H}=0.500$
Numerical Result
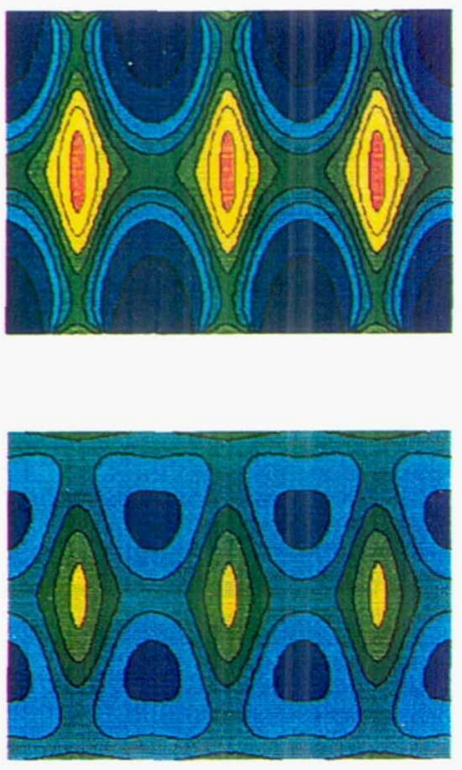

Figure 4: Concentration Distributions for a Square Orifice Configuration (Plate 3, Table 1) at $\mathrm{S} / \mathrm{H}=0.425 . \mathrm{J}=36$ 
Page intentionally left blank 


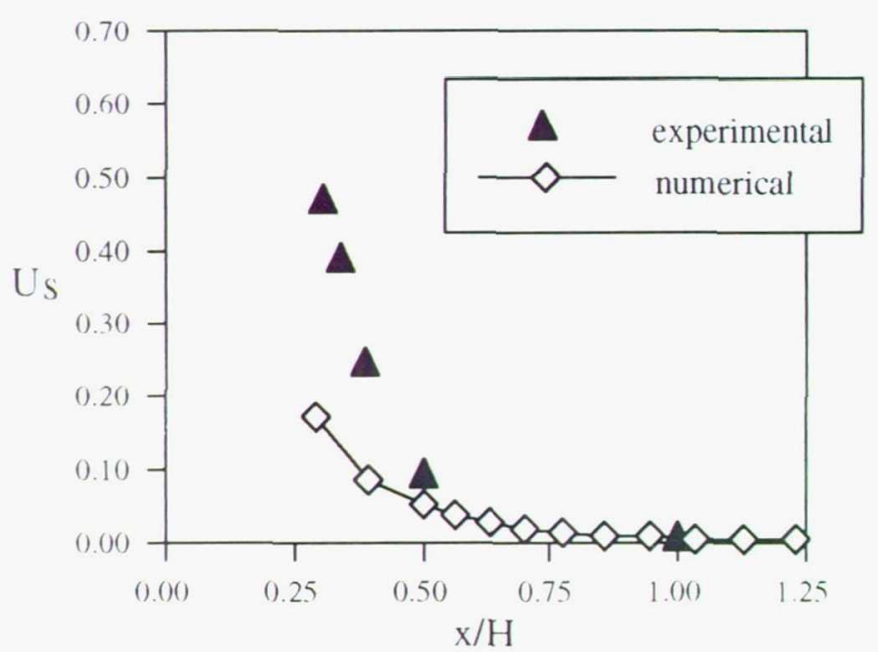

Figure 5: Comparison of Spatial Unmixedness for a Square Orifice Configuration (Plate 3 in Table 1) at $\mathrm{I}=36$ and $\mathrm{S} / \mathrm{H}=0.425$

\section{Effect of ()rifice Shape}

('rossflow jet mixing performance is directly related to jet penetration with optimum mixing for inline configurations occuring when the asymptotic mean trajectory is at $\mathrm{H} / 4$ Previous studies ${ }^{8} 12$ of a slot with an aspect ratio (long-toshort) $>2$ have shown that jet penetration may be a function of orifice angle. Therefore in addition to orifice spacing, slot angle cam be used to modify jet penetration. The characteristics of inline $45^{\circ}$ slanted slots (aspect ratio 4:1) and round holes were investigated to show the effect of orifice shape on mixing.

Drawings of the two configurations and their corresponding concentration distributions at $\mathrm{x} / \mathrm{H}=0.5$ are shown in Fig. 6. The orifices are equal in area. however the round orifice spacing was decreased to reduce jet penetration so that it was equal to that of the slanted slot case. In each case the jets penetrate to about $1 / 4$ of the duct height and mixing is similar as indicated by the comparable values of $\mathrm{U}_{\mathrm{s}}$ shown in Fig. 7. Although orifice shape modifies the jet concentration distribution in the vicinity of injection, downstream mixing appears to be independent of shape for slanted slots and round holes. if aerodynamically equivalent cases are compared.
The results are presented to show that equivalent mean concentration distributions are not obtained at equal spacing for equal $J$. Therefore conclusions about the effect of orifice shape on multiple jet configurations can only be made from comparison of optimized configurations.

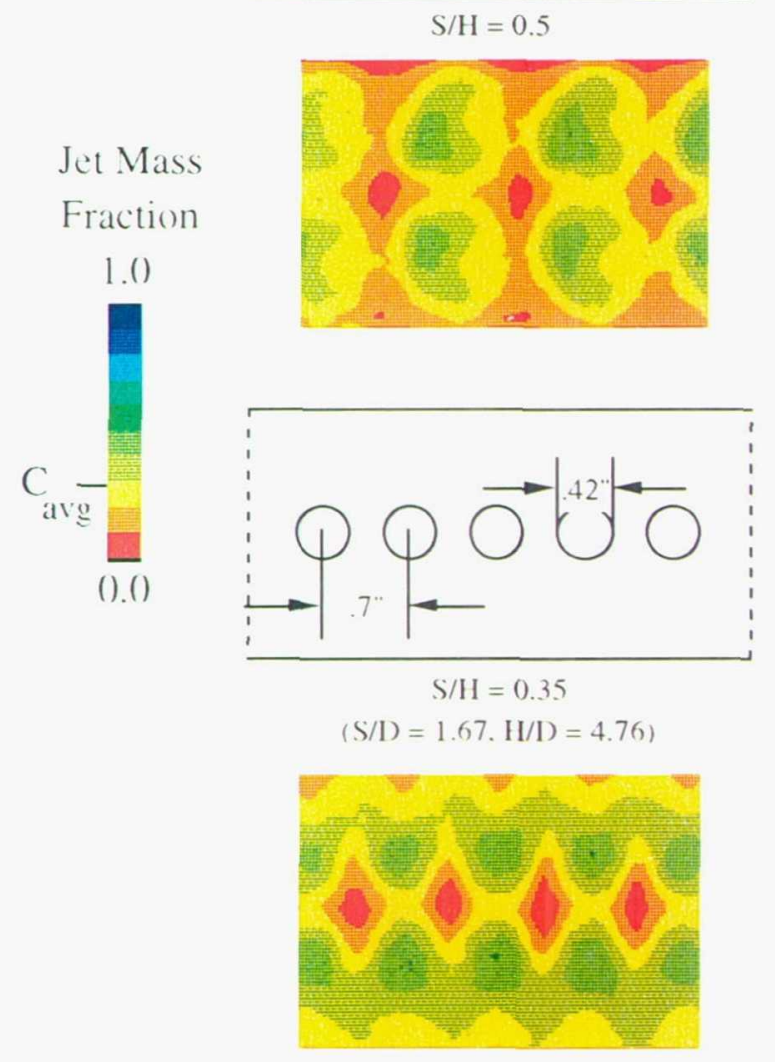

Figure 6: Orifice Configurations and Concentration Distributions for $45^{\circ} 4: 1$ slots and Round Holes at $\mathrm{x} / \mathrm{H}=0.5$ and $\mathrm{J}=2.5$ 
Page intentionally left blank 


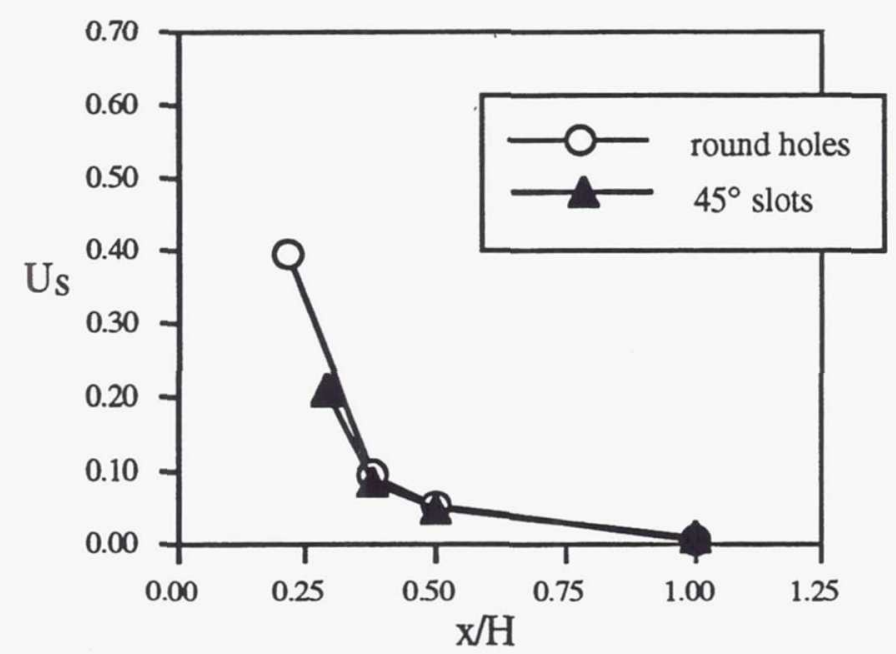

Figure 7: Comparison of Spatial Unmixedness for Equivalent $45^{\circ}$ Slot and Round Hole Configurations at $\mathrm{J}=25$

\section{Effect of Unequal Opposed Values of J}

Annular combustors typically have an equal number of orifices on the ID and OD walls. Therefore in addition to an OD webb that is larger than the $\mathrm{ID}$ webb the local MR varies radially. The use of different diameter (and/or number) of orifices on the opposing walls may be considered to circumferentially distribute the jet fluid more uniformly. A design with different $\mathrm{ID} / \mathrm{OD}$ jet areas might result in different $\mathrm{ID} / \mathrm{OD}$ values for $\mathrm{J}$.

The effect of varying opposing $\mathrm{J}$ values is compared to results of an empirical study ${ }^{19}$ in Fig. 8. In this experiment the orifice plate configuration was constant: $D=0.25$ and S/ $\mathrm{H}=0.25$ while the opposing $\mathrm{J}$ values were varied to maintain a constant MR of 0.325 . This orifice configuration was found to be an optimum inline configuration when opposing values of $\mathrm{J}$ were equal and also an optimum configuration for single sided injection at the same MR. The concentration distributions vary as expected in that jet penetration is proportional to $J$. The values of $U_{s}$ at $x / H=0.5$ was about 0.03 for all cases although the circumferential profiles are distinctly different. The experimental and empirical results are in good agreement.

\section{Conclusions}

1. Compared at $x / \mathrm{H}=0.5$, orifice configurations with blockages ranging from 0.59 to 0.89 had similar mixing performance.

2. The design correlation for inline configurations at $\mathrm{MR}=2, \quad 2.5 \approx(\mathrm{S} / \mathrm{H}) \sqrt{\mathrm{J}}$, is independent of the webb between adjacent orifices.

3. Numerical and experimental results were in good agreement for an orifice with aspect ratio of 1-to-1.

4. Conclusions about the performance of various orifice shapes can only be obtained from comparison of optimized configurations.

5. Experimental and empirical results were in good agreement for jets with different momentum-flux ratios on opposite sides.

\section{Acknowledgements}

This work was supported by NASA Contract NAS3-25954, Task Order \#12. 
Page intentionally left blank 
Experimental

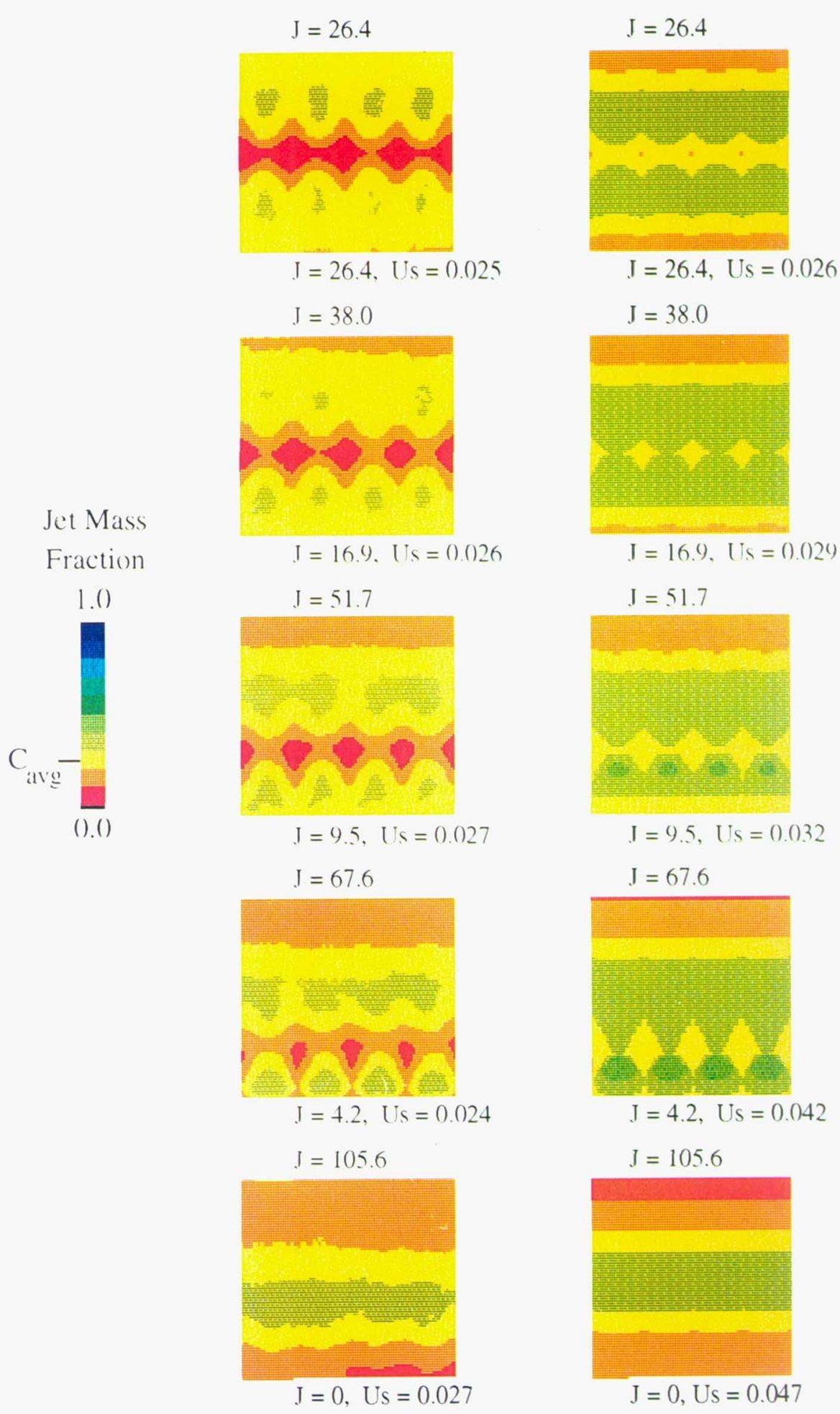

Figure 8: Comparison of Experimental and Empirical Results for Inline Round Orifices when Opposing I Values are Unequal $(\mathrm{S} / \mathrm{H}=0.25$ and $\mathrm{x} / \mathrm{H}=0.5)$ 
Page intentionally left blank 


\section{References}

1. Shaw, R.J., "Engine Technology Challenges for a 21st Century High Speed Civil Transport," AIAA 1Oth International Symposium on Air Breathing Engines, September 1-6, 1991 (also NASA TM 104361).

2. Bain, D.B., Smith, C.E., and Holdeman, J.D., "CFD Assessment of Orifice Aspect Ratio and Mass Flow Ratio on Jet Mixing in Rectangular Ducts," AIAA 94-0218, Reno, Nevada, Jan. 10-13, 1994 (also NASA TM 106434).

3. Oechsle, V.L., Mongia, H.C., and Holdeman, J.D., "Comparison of the Mixing Calculations for Reacting and NonReacting Flows in a Cylindrical Duct," AIAA 94-0865, Reno, Nevada, Jan. 10-13, 1994 (also NASA TM 106435.

4. Sowa, W.A., Kroll, J.T., and Samuelsen, G.S., "Optimization of Orifice Geometry for Cross-Flow Mixing in a Cylindrical Duct," AIAA 94-0219, Reno, Nevada, Jan. 10-13, 1994 (also NASA TM 106436).

5. Doerr, Th. and Hennecke, D.K., "The Mixing Process in the Quenching Zone of the Rich-Lean Combustion Concept," AGARD-PEP $81^{\text {st }}$ Symposium of Fuels and Combustion Technology for Advanced Aircraft Engines, 1993.

6. Bain, D.B., Smith, C.E., and Holdeman, J.D., "CFD Mixing Analysis of Axially Opposed Rows of Jets Injected into a Confined Crossflow," AIAA 93-2044, Monterey, CA, June 28-30, 1993 (also NASA TM 106179).

7. Liscinsky, D.S., True, B., and Holdeman, J.D., "Experimental Investigation of Crossflow Jet Mixing in a Rectangualr Duct," AIAA 93-2037, Monterey, CA, June 28-30, 1993 (also NASA TM 106152).

8. Oechsle, V.L., Mongia, H.C., and Holdeman, J.D., "An Analytical Study of Jet Mixing in a Cylindrical Duct," AIAA 93-2043, Monterey, CA, June 28-30, 1993 (also NASA TM 106181).

9. Kroll, J.T., Sowa, W.A., Samuelsen, G.S., and Holdeman, J.D., "Optimization of Circular Orifice Jets Mixing into a Heated Crossflow in a Cylindrical Duct," AIAA 93-0249, Reno, Nevada, Jan. 11-14, 1993 (also NASA TM 105984).

10. Bain, D.B., Smith, C.E., and Holdeman, J.D., "CFD Mixing Analysis of Jets Injected from Straight and Slanted Slots into Confined Crossflow in Rectangular Ducts," AIAA 92-3087, Nashville, TN, July 6-8, 1992 (also NASA TM 105699).
11. Liscinsky, D.S., True, B., Vranos, A., and Holdeman, J.D., "Experimental Study of Cross-Stream Mixing in a Rectangular Duct," AIAA Paper 92-3090, Nashville, TN, July 6-8, 1992 (also NASA TM 106194).

12. Oechsle, V.L., Mongia, H.C., and Holdeman, J.D., "A Parametric Numerical Study of Mixing in a Cylindrical Duct," AIAA 92-3088, Nashville, TN, July 6-8, 1992 (also NASA TM 105695).

13. Hatch, M.S., Sowa, W.A., Samuelsen, G.S., and Holdeman, J.D., "Jet Mixing Into a Heated Cross Flow in a Cylindrical Duct: Influence of Geometry and Flow Variations," AIAA 92-0773, Reno, Nevada, Jan. 6-9, 1992 (also NASA TM 105390).

14. Smith, C.E., Talpallikar, M.V., and Holdeman, J.D., "A CFD Study of Jet Mixing in Reduced Areas for Lower Combustor Emissions," AIAA Paper 91-2460, Sacramento, CA, June 1991 (also NASA TM 104411).

15. Vranos, A., Liscinsky, D.S., True, B., and Holdeman, J.D., "Experimental Study of Cross-Stream Mixing in a Cylindrical Duct," AIAA 91-2459, Sacramento, CA, June 24-27, 1991 (also NASA TM 105180).

16. Talpallikar, M.V., Smith, C.E., Lai, M.C., and Holdeman, J.D., "CFD Analysis of Jet Mixing in Low $\mathrm{NO}_{x}$ Flametube Combustors," J. Eng. Gas Turbine Pwr., 114, 416, 1992, (also ASME 91-217, 1991 and NASA TM 104466).

17. Holdeman, J.D., "Mixing of Multiple Jets with a Confined Subsonic Crossflow," Prog. Energy Combust. Sci., 19, p31-70, 1993 (also AIAA 91-2458, Sacramento, CA, June 1991 and NASA TM 104412).

18. Smith, C.E., "Mixing Characteristics of Dilution Jets in Small Gas Turbine Combustors," AIAA 90-2728, Orlando, Fl, July 16-18, 1990.

19. Holdeman, J.D., and Srinivasan, R., "Perspectives on Dilution Jet Mixing," AIAA-86-1611, Huntsville, AL, March 1986, (also NASA TM 87294).

20. Liscinsky, D.S. and True, B. "Planar Mie Scattering Measurements of Scalar Mixing," SPIE Proceedings Vol. 2122-18, Los Angeles, CA, Jan. 25-26, 1994. 


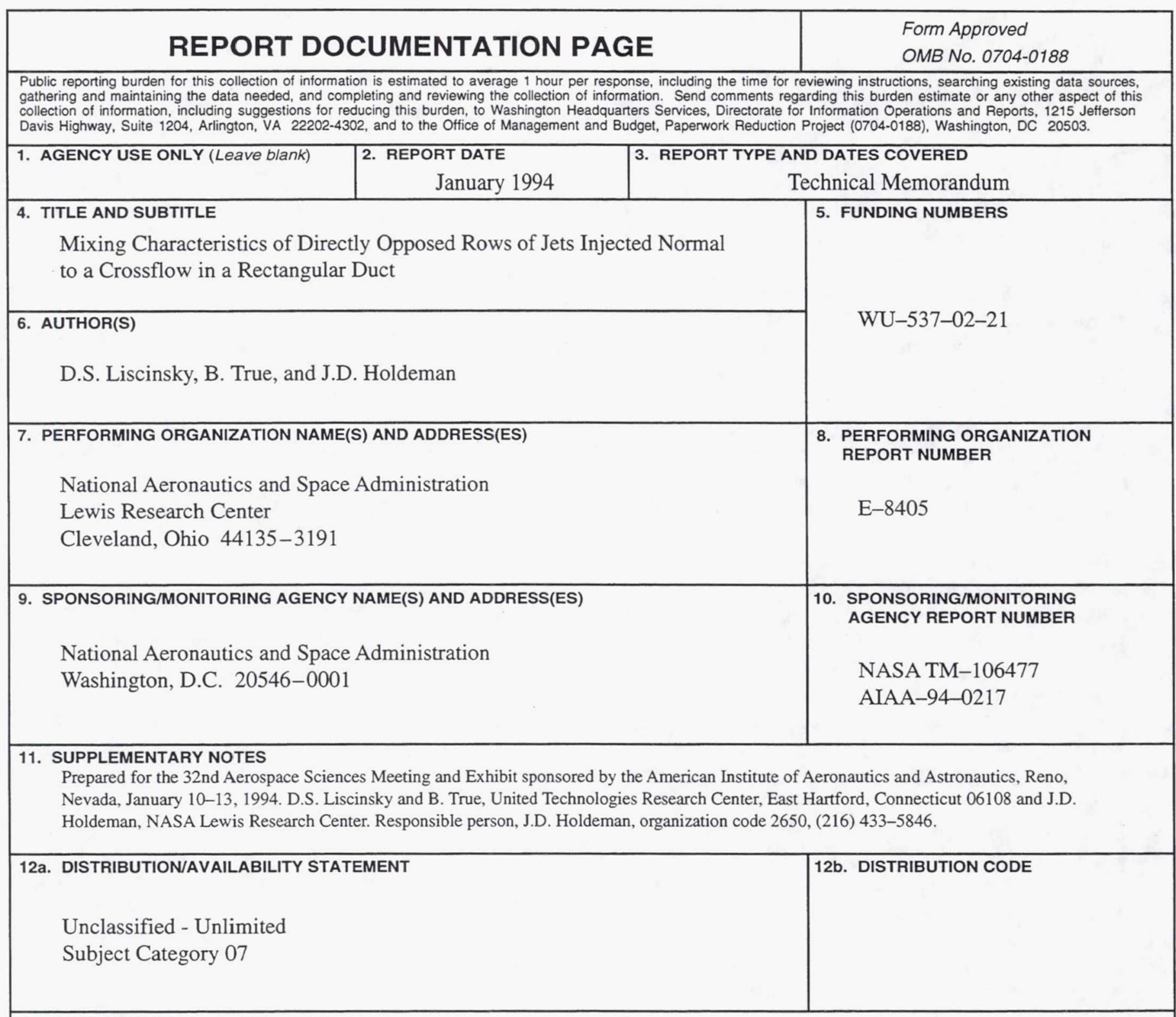

13. ABSTRACT (Maximum 200 words)

An experimental investigation of the mixing of nonreacting opposed rows of inline jets injected perpendicular to a uniform crossflow has been conducted in a rectangular duct. Planar Mie-scattering was used to measure the time-average concentration distribution of the jet fluid in planes perpendicular to the duct axis. Orifice configurations with geometric blockages ranging from 0.59 to 0.89 had similar mixing performance when compared at one-half duct height downstream of injection. Blockage was varied by changing the orifice aspect ratio from 1-to-1 to 1-to-1.5 while maintaining orifice spacing-to-duct height $(\mathrm{S} / \mathrm{H})$ at 0.425 , jet-to-mainstream mass flow ratio $(\mathrm{MR})$ at 2.0 , and jet-to-mainstream momentum-flux ratio $(\mathrm{J})$ at 48 . The result indicates that the design correlating expression (at $\mathrm{MR}=2$ ) for optimum inline mixing of $2.5 \approx(\mathrm{S} / \mathrm{H}) \sqrt{\mathrm{J}}$ is independent of the webb between adjacent orifices and therefore independent of orifice width. Experimental and numerical results for an orifice aspect ratio 1-to-1 case were in good agreement. The results of a comparison of inline $45^{\circ}$ slanted slot and round orifice configuration indicate that in order to obtain equivalent mean concentration distributions at the same $\mathrm{J}$ it is necessary to use a smaller $\mathrm{S} / \mathrm{H}$ for the round orifice configuration. Conclusions about the performance of various orifice shapes can only be obtained from comparison of optimized configurations. Inline jets with different momentum-flux ratios on opposite sides were compared at a constant mass flow ratio. The orifice spacing choosen was previously found to be an optimum configuration when opposing values of $\mathbf{J}$ were equal and also an optimum for single side injection. Experimental and empirical results were in good agreement.

14. SUBJECT TERMS

Dilution; Jet mixing; Gas turbine; Emissions; Combustion chamber

15. NUMBER OF PAGES

17. SECURITY CLASSIFICATION OF REPORT Unclassified
18. SECURITY CLASSIFICATION OF THIS PAGE Unclassified
19. SECURITY CLASSIFICATION OF ABSTRACT

Unclassified 